\title{
Review Article \\ Research on Ecological Restoration Mechanism of Rare-Earth Mines Based on Evolutionary Game
}

\author{
Guangli Yan $\mathbb{D D}^{1,2}$ Fei Xue, $^{2}$ and Zhongxue Li ${ }^{1}$ \\ ${ }^{1}$ School of Civil and Resource Engineering, University of Science and Technology Beijing, Beijing 100083, China \\ ${ }^{2}$ Jiangxi University of Science and Technology, Ganzhou 341000, China \\ Correspondence should be addressed to Zhongxue Li; zxli@ustb.edu.cn
}

Received 25 December 2019; Revised 13 February 2020; Accepted 24 February 2020; Published 30 March 2020

Academic Editor: Hossein Moayedi

Copyright (c) 2020 Guangli Yan et al. This is an open access article distributed under the Creative Commons Attribution License, which permits unrestricted use, distribution, and reproduction in any medium, provided the original work is properly cited.

With the continuous improvement of the rare earth's international status, the status of rare Chinese earth has gradually become prominent all over the world. When China enjoys the advantages of large reserves of rare-earth resources, at the same time, Chinese rare-earth enterprises are lagging in technology and lacking innovation capabilities. The rare-earth industry is mainly concentrated on the separation and smelting process, which has an indelible impact on the ecological environment around the mine. Some scholars have carried out research on ecological restoration in mining areas, but there are few studies on interest subjects in ecological restoration work in mining areas, especially the research based on game theory is more scarce. This article constructs a trilateral evolutionary game model of the central, local governments, and mining enterprises. This article analyzes the impact mechanism of policy changes on the rare-earth mining industry and analyzes the three-party evolutionary game model by adjusting the values of external variables. The research shows that the central government's subsidies to local enterprises, the central government's performance evaluation to the government, the local government's punishment to enterprises, and the local enterprise's reproduction income are important factors that determine the evolution of the trilateral game. Therefore, the central government should strengthen the supervision of local governments and enterprises when formulating policies related to the rareearth industry, and local governments should strengthen their own management and local environmental regulations.

\section{Introduction}

With the development of economy and society, the advantages of local governments in the regional resources have gradually expanded, especially when central governments and the local government have different development goals. Local governments are more inclined to sacrifice the ecological environment for GDP growth and get high marks in local performance. "The Environmental Protection Law of the People's Republic of China," "The Soil Pollution Control Law of the People's Republic of China," "The Mineral Resources Law of the People's Republic of China," and several legal documents were issued around the 18th National Congress of the People's Republic of China. These legal documents promote the construction of ecological civilization to a high status. Gradually, the central government and local governments generate a game relationship in environmental governance, and this game relationship is gradually passed to the rare-earth enterprises along with the resource chain and information chain [1]. As a new era, strategic resource, ionic rare-earth was listed as a protective mining species 50 years ago. Its unique strategic value and broad market value have attracted much attention from the ionic rare-earth industry. The ionic rare-earth industry has become one of China's core mining industries, with the continuous deepening of processes such as mining, smelting, and processing. However, the development of rare ionic earth in the south of China in recent years is not optimistic [2]. Current mining technologies have limited the progress and efficiency of ionic precious earth mining. At the same time, environmental problems have not been effectively resolved, for instance, soil fertility degradation, land desertification, heavy metal pollution, landslides, and groundwater ammonia nitrogen standards. When facing 
increasingly severe environmental governance situations and international trade pressures, the government needs to rapidly solve the problem which is developing a practical and feasible environment mechanism.

In recent years, the rapid development of computing technology has promoted the depth of academic research, and using algorithms for predictive analysis of actual cases has become the mainstream of academic research. Niu et al. [3] proposed a new short-term electricity price hybrid forecasting model based on the wavelet transform and differential autoregressive moving average theory. Qiao et al. [4] offered a hybrid prediction model that has a better ability to jump out of local optimum and has higher prediction accuracy when the amount of data is larger or smaller. Jie et al. [5] performed analysis to analyze the effects of internal gas pressure and the ratio of the long axis to the short axis on the stability of SSTW caverns. Some scholars used the model to accurately predict PM2.5 based on WT-SAE-LSTM [6], quantum dolphin swarm algorithm to solve the optimal solution of large-scale functions [7], and chaotic dolphin swarm algorithm [8] or a novel algorithm based on kernel fuzzy C-means and dolphin swarm algorithm [9] to solve high-dimensional function optimization problems, and so on [10-12, 27].

Similarly, in the study of rare-earth environmental regulations, researchers have gradually realized the importance of establishing mathematical models for research. In order to solve the problem of universal applicability evaluation of green mine construction standards and effects, Zhong et al. [13] constructed an evaluation index system for green mines in the nonferrous metal industry and evaluated the degree of green mine construction with the fuzzy mathematical comprehensive evaluation method based on six levels of mining environment resource development methods, comprehensive utilization of resources, energy conservation and emission reduction, technological innovation, and enterprise management. Zheng et al. [14] took the water environmental cost of ionic rare-earth mines as a research object, established a water environment pollution loss model, and quantified the water environmental costs of 12 ionic rare-earth mines in southern Jiangxi. At the same time, they analyzed the relationship between the production scale of ionic rare-earth mines and the cost of water environment, compiled measurement formulas, and drawn up a quick checklist of the cost of the water environment under different production scales. According to the scale of mine production, the water environment cost can be quickly found by every researcher. Su et al. [15] built a set of rare-earth enterprises' environmental performance evaluation index system and fuzzy comprehensive evaluation model based on the environmental standards of China's rare-earth industry combined with the current status and requirements of environmental protection and evaluation of Chinese rare-earth enterprises. They also expected that the model can be used to quantify the role of rare-earth companies in the environment, guide rare-earth companies to actively disclose more environmental information, conduct environmental performance management, and achieve sustainable development. Xu et al. [16] established an evaluation index system for the ecological security of ionic rare-earth mining areas based on the PSR framework model and analyzed and evaluated the ecological security situation of a rare-earth mining area in Ganzhou from 2011 to 2016. The study found that the overall ecological security index of the rare-earth mining area showed an upward trend, indicating that the ecological security status of the mining area is gradually improving, but the ecological security status of the area as a whole has not reached the ideal security status. Yu et al. [17] focused on the typical rare-earth mining areas in southern Jiangxi, took rock and weathered crust and tailings and water as the research system and used a multidisciplinary and multimethod approach to conduct a systematic study of the resource-environment effects involved in the exploitation of ion-adsorbed rare-earth resources. In the context of environmental regulation and taxation, there have been an increasing number of studies using evolutionary games to analyze the relationship between government and enterprises. For example, Wang and Zhang [18] used the theory of planned behavior to explore the degree of internal logic and interaction between command and control and market incentives and the willingness and the role of green technology innovation in environmental regulation. Feng et al. [19] obtained three factors that influence the local government's environmental regulation strategy by exploring the behavioral evolutionary stabilization strategies of local governments, sewage companies, and the central government, such as the cost of implementing environmental regulations, penalties by the central government, and the cost of pollution control by sewage companies. Chen and Wang [20] and Pan et al. [21] analyzed the evolutionary game model of the central government, local governments, and polluting enterprises in the context of the environmental tax system and found that the intensity of supervision and environmental taxes will affect the emissions of polluting enterprises.

By reviewing the existing research results, it can be known that, in terms of research methods, most of the literature research focuses on the identification of rareearth environmental regulatory indicators, the establishment of evaluation systems, and cost quantification [22]. Few studies have analyzed rare-earth mines from a game perspective, as well as the relative lack of research on the influencing factors of environmental protection consciousness and execution ability of mining enterprises $[23,24]$. Although there have been related environmental regulation studies using game theory, the research methods are mostly static games, and few studies have established simulation dynamic models. On the basis of previous studies, this paper takes the ionic rare-earth ecological environment in southern Jiangxi as the main body of interest, constructs a three-party evolutionary game model of the central government, local government, and local mining enterprises, and uses evolutionary game theory to dynamically study the strategic changes among the three [25]. At the same time, this paper combines the actual state of ionic rare-earth environment governance in China, compares the influence of different reward and punishment mechanisms of the central government on the behavior of local governments in Gannan and rareearth mining companies, and provides a theoretical basis for the construction of the environmental governance mechanism in the southern part of Jiangxi. 


\section{Constructing Evolutionary Game Models}

Hypothesis 1. The three players in the game model are the central government, local government, and enterprises. The central government participates in the game as a regulator, the local government participates in the game as a policy executor, and the enterprise participates in the game as an implementer of ecological restoration [26]. In order to avoid fines, local enterprises will seek opportunities to bribe local governments to form collusion with local governments. This action can bring additional benefits to businesses and governments, but once the central government finds collusion between local governments and enterprises, it will severely punish local governments and the companies involved.

Hypothesis 2. In this game model, the central government has two strategies in the game [27]: the central government's strict supervision of the local government is recorded as $x(0<x<1)$ or the local government's loose supervision of the local government is recorded as $1-x$, and the company will have two strategies: repair the environment, denoted as $y(0<y<1)$, or not repair the environment, denoted as $1-y$. Similarly, two strategies of the local government are in the game: monitor corporate behavior is recorded as $z(0<z<1)$ or not monitor corporate behavior which is recorded as $1-z$.

Hypothesis 3. When the mining enterprise carries out the rare-earth mining work, the net income is $\Delta S_{E 0}$. When an enterprise adopts the "repair" strategy, the costs of purchasing pollution treatment equipment and introducing new technologies are recorded as $C_{E 1}$, the social benefits of the enterprise are documented as $S_{E 1}$, the income from technological innovation for energy conservation and environmental protection are recorded as $S_{E 2}$, and the local government is actively carrying out ecological restoration, and mining enterprises are given administrative rewards which are recorded as $F_{E 1}$; when the company does not repair the environment, if the local government performs supervision duties, the company will face penalties, which are recorded as $K_{E 1}$, including fines or warnings, and the hidden loss of corporate reputation due to environmental damage [28]. The social benefits are recorded as $K_{E 2}$. Of course, as a rational player in profit-seeking, if there is an opportunity recorded as $\theta$ for the enterprise to successfully bribe local government personnel, the enterprise will be exempted from punishment when the ecological restoration is not carried out, and the cost of bribery will be recorded $H$.
Hypothesis 4. When the local government adopts a "monitor" strategy, it will strictly monitor the environment of rare-earth mines. When mining companies do not carry out the ecological restoration work, the government receives the taxes which are recorded as $T_{G 0}$ paid by mining companies, the environmental management costs are recorded as $C_{G 1}$, the compensation for residents in the surrounding communities are recorded as $C_{E 2}$, and the cost of supervision is recorded as $C_{G 0}$. Because the mining enterprises expand reproduction, enterprises gain additional tax paid recorded as $T_{G 1}$, and when the local government does "not monitor" the strategy, the enterprise does not repair and the local government's credibility recorded as $C_{G 3}$ is lost [29].

Hypothesis 5. The central government's revenue from the local government and corporate taxes are recorded as $S_{Z 0}$. The central government's penalties for unregulated local governments are recorded as $K_{Z 1}$. When the government and the enterprise collude, the central government will increase the punishment recorded as $\alpha$, and the timely punishment of the local government has also increased the trust, recorded as $K_{Z 2}$, of the public in the central government. The central government ordered the local government to provide economic compensation to the residents around the mining which is recorded as $C_{Z 1}$. When the central government chose the "easy supervision" policy, it led to public doubts about the ability and level of government departments to work, recorded as $C_{Z 2}$, which led to a decline in social credibility. When the mining company has a good repair work, the cost of organizing personnel to study at the central government is recorded as $C_{Z 3}$, and administrative rewards for local enterprises are recorded as $F_{E 2}$. In the actual supervision process of the central government, the supervision cost is $C_{Z 0}$. Table 1 and 2 are the game strategy combinations of the central government, local governments, and enterprises.

\section{Analysis of Evolutionary Game Strategy}

This section first calculates the evolutionary analysis of the strategic choices of the central government, local governments, and mining enterprises, then comprehensively analyzes the evolutionary stability strategy of the entire game system, and analyzes the influencing factors of the evolutionary stability strategy of the game system in detail [30]. Before doing evolutionary game analysis, the expected returns of participants choosing different strategies and the average returns of all strategies need to be calculated. First, calculate the benefits of the central government's choice of a "regulatory" strategy $U_{x}$ :

$$
\begin{aligned}
U_{x}= & y z\left(S_{Z 0}-C_{Z 0}-C_{Z 3}-F_{E 2}\right)+y(1-z)\left(S_{Z 0}-C_{Z 0}-C_{Z 3}-F_{E 2}+K_{Z 1}+K_{Z 2}\right)+z(1-y)\left(S_{Z 0}-C_{Z 0}\right. \\
& \left.+\theta\left(\alpha K_{Z 1}+K_{Z 2}\right)+(1-\theta) K_{Z 1}\right)+(1-y)(1-z)\left(S_{Z 0}-C_{Z 0}+K_{Z 1}+K_{Z 2}\right) \\
= & -y z\left(\theta\left(\alpha K_{Z 1}+K_{Z 2}\right)+(1-\theta) K_{Z 1}\right)-y\left(C_{Z 3}+F_{E 2}\right)+z\left(\theta\left(\alpha K_{Z 1}+K_{Z 2}\right)-\theta K_{Z 1}-K_{Z 2}\right)+S_{Z 0}-C_{Z 0}+K_{Z 1}+K_{Z 2} .
\end{aligned}
$$


TABLE 1: Tripartite game strategy combinations under the supervision $(x)$ of the central government.

\begin{tabular}{lcc}
\hline & Enterprise repair $y$ & Enterprise does not repair 1-y \\
\hline Local government monitor $z$ & $S_{Z 0}-C_{Z 0}-C_{Z 3}-F_{E 2} ;$ & $S_{Z 0}-C_{Z 0}+\theta\left(\alpha K_{Z 1}+K_{Z 2}\right)+(1-\theta) K_{Z 1} ;$ \\
& $\Delta S_{E 0}-C_{E 1}+S_{E 1}+S_{E 2}+F_{E 1}-T_{G 0}+F_{E 2} ;$ & $\Delta S_{E 0}-T_{G 0}+\theta\left(S_{E 3}-H\right)-(1-\theta)\left(K_{E 1}+C_{E 2}\right)-K_{E 2} ;$ \\
& $T_{G 0}-C_{G 0}-F_{E 1}$ & $T_{G 0}-C_{G 0}-C_{G 1}-C_{Z 1}+\theta\left(H-\alpha K_{Z 1}-C_{G 3}\right)$ \\
\hline \multirow{2}{*}{$\begin{array}{c}\text { Local government does not monitor } \\
1-z\end{array}$} & $S_{Z 0}-C_{Z 0}-C_{Z 3}-F_{E 2}+K_{Z 1}+K_{Z 2} ;$ & $+\Delta T_{G 2}+(1-\theta) K_{E 1}$ \\
\hline & $\Delta S_{E 0}-C_{E 1}+S_{E 1}+S_{E 2}+F_{E 2}-T_{G 0} ;$ & $S_{Z 0}-C_{Z 0}+K_{Z 1}+K_{Z 2} ;$ \\
\hline
\end{tabular}

TABLE 2: Tripartite game strategy combinations without supervision $(1-x)$ by the central government.

\begin{tabular}{lcc}
\hline & Enterprise repair $y$ & Enterprise does not repair 1-y \\
\hline & $S_{Z 0} ;$ & $S_{z 0}-C_{z 2} ;$ \\
Local government monitor $z$ & $\Delta S_{E 0}-C_{E 1}+S_{E 1}+S_{E 2}+F_{E 1}-T_{G 0} ;$ & $S_{E 0}-T_{G 0}+\theta\left(S_{E 3}-H\right)-(1-\theta)\left(K_{E 1}+C_{E 2}\right)-K_{E 2} ;$ \\
& $T_{G 0}-C_{G 0}-F_{E 1}$ & $T_{G 0}-C_{G 0}-C_{G 1}+\theta\left(H-C_{G 3}\right)+T_{G 1}+(1-\theta) K_{E 1}$ \\
\hline & $S_{Z 0} ;$ & $S_{Z 0}-C_{Z 2} ;$ \\
Local government does not monitor $1-z$ & $\Delta S_{E 0}-C_{E 1}+S_{E 1}+S_{E 2}-T_{G 0} ;$ & $\Delta S_{E 0}+S_{E 3}-K_{E 2}-T_{G 0} ;$ \\
& $T_{G 0}$ & $T_{G 0}-C_{G 3}$ \\
\hline
\end{tabular}

Then, calculate the benefits of the central government's choice of "no regulation" $U_{1-x}$ :

$$
\begin{aligned}
U_{1-x}= & y z\left(S_{Z 0}\right)+z(1-y)\left(S_{Z 0}-C_{Z 2}\right)+y(1-z)\left(S_{Z 0}\right) \\
& +(1-y)(1-z)\left(S_{Z 0}-C_{Z 2}\right)=S_{Z 0}-C_{Z 2} .
\end{aligned}
$$
$\overline{E_{x}}$ :

The average expected return of the central government is

$$
\overline{E_{x}}=x U_{x}+(1-x) U_{1-x} .
$$

Therefore, it is possible to calculate the replication dynamic equation of the central government's choice of the "supervision" strategy:

$$
\begin{aligned}
\frac{\mathrm{d} x}{\mathrm{~d} t}= & F(x)=x\left(U_{x}-\overline{U_{x}}\right)=x(1-x)\left(U_{x}-U_{1-x}\right) \\
= & x(1-x)\left\{-y z\left[\theta\left(\alpha K_{Z 1}+K_{Z 2}\right)+(1-\theta) K_{Z 1}\right]\right. \\
& -y\left(C_{Z 3}+F_{E 2}\right)+z\left[\theta\left(\alpha K_{Z 1}+K_{Z 2}\right)-\theta K_{Z 1}-K_{Z 2}\right] \\
& \left.+K_{Z 1}+K_{Z 2}\right\} .
\end{aligned}
$$

Furthermore, calculate the benefits of mining companies choosing the "repair" strategy $U_{y}$ :

$$
\begin{aligned}
U_{y}= & x z\left(S_{E 0}-C_{E 1}+S_{E 1}+S_{E 2}+F_{E 1}-T_{G 0}+F_{E 2}\right)+x(1-z)\left(S_{E 0}-C_{E 1}+S_{E 1}+S_{E 2}+F_{E 2}-T_{G 0}\right) \\
& +z(1-x)\left(S_{E 0}-C_{E 1}+S_{E 1}+S_{E 2}+F_{E 1}-T_{G 0}\right)+(1-x)(1-z)\left(S_{E 0}-C_{E 1}+S_{E 1}+S_{E 2}-T_{G 0}\right) \\
= & x F_{E 2}+z F_{E 1}+S_{E 0}-C_{E 1}+S_{E 1}+S_{E 2}-T_{G 0} .
\end{aligned}
$$

Then, calculate the benefits of mining companies choosing "not repair" $U_{1-y}$ :

$$
\begin{aligned}
U_{1-y}= & x z\left(S_{E 0}-T_{G 0}+\theta\left(S_{E 3}-H\right)-(1-\theta)\left(K_{E 1}+C_{E 2}\right)-K_{E 2}\right)+x(1-z)\left(S_{E 0}-T_{G 0}+S_{E 3}-K_{E 2}\right) \\
& +z(1-x)\left(S_{E 0}-T_{G 0}+\theta\left(S_{E 3}-H\right)-(1-\theta)\left(K_{E 1}+C_{E 2}\right)-K_{E 2}\right)+(1-x)(1-z)\left(S_{E 0}+S_{E 3}-K_{E 2}-T_{G 0}\right) \\
= & S_{E 0}+S_{E 3}-K_{E 2}-T_{G 0} .
\end{aligned}
$$

The average expected return of a mining company is

$$
\overline{E_{y}}: \overline{E_{y}}=y U_{y}+(1-y) U_{1-y} .
$$

(7) Therefore, the replication dynamic equation of the mining company's "repair" strategy can be calculated as

$$
\begin{aligned}
\frac{\mathrm{d} y}{\mathrm{~d} t} & =F(y)=y\left(U_{y}-\overline{U_{y}}\right)=y(1-y)\left(U_{y}-U_{1-y}\right) \\
& =y(1-y)\left(x F_{E 2}+z F_{E 1}+S_{E 1}+S_{E 2}-S_{E 3}+K_{E 2}-C_{E 1}\right) .
\end{aligned}
$$


Finally, calculate the benefits of the local government's "execute" strategy $U_{z}$ :

$$
\begin{aligned}
U_{z}= & x y\left(T_{G 0}-C_{G 0}-F_{E 1}\right)+x(1-y)\left(T_{G 0}-C_{G 0}-C_{G 1}-C_{Z 1}+\theta\left(H-\alpha K_{Z 1}-C_{G 3}\right)+T_{G 1}+(1-\theta) K_{E 1}\right) \\
& +y(1-x)\left(T_{G 0}-C_{G 0}-F_{E 1}\right)+(1-x)(1-y)\left(T_{G 0}-C_{G 0}-C_{G 1}+\theta\left(H-C_{G 3}\right)+T_{G 1}+(1-\theta) K_{E 1}\right) \\
= & x y \theta \alpha K_{Z 1}-x \theta \alpha K_{Z 1}+y\left[C_{G 1}-\theta\left(H-C_{G 3}\right)-T_{G 1}-(1-\theta) K_{E 1}-F_{E 1}\right]+T_{G 0}-C_{G 0}-C_{G 1}+\theta\left(H-C_{G 3}\right) \\
& +T_{G 1}+(1-\theta) K_{E 1} .
\end{aligned}
$$

Then, calculate the benefits of local governments choosing not to execute $U_{1-z}$ :

$$
\begin{aligned}
U_{1-z} & =x z\left(T_{G 0}-C_{G 0}-K_{Z 1}-C_{G 3}\right)+x(1-y)\left(T_{G 0}-C_{G 0}-K_{Z 1}-C_{G 3}\right)+y(1-x)\left(T_{G 0}\right)+(1-x)(1-y)\left(T_{G 0}-C_{G 3}\right) \\
& =-x y C_{G 3}-x\left(C_{G 0}+K_{Z 1}\right)+y C_{G 3}+T_{G 0}-C_{G 3} .
\end{aligned}
$$

The average expected return of a local government is $\overline{E_{z}}$ :

$$
\overline{E_{z}}=z U_{z}+(1-z) U_{1-z} .
$$

Therefore, it is possible to calculate the replication dynamic equation of the local government's "execute" strategy:

$$
\begin{aligned}
\frac{\mathrm{d} z}{\mathrm{~d} t}= & F(z)=z\left(U_{z}-\overline{U_{z}}\right)=z(1-z)\left(U_{z}-U_{1-z}\right) \\
= & z(1-z)\left\{x y\left(\theta \alpha K_{Z 1}+C_{G 3}\right)+x\left(C_{G 0}+K_{Z 1}-\theta \alpha K_{Z 1}\right)+y\left[C_{G 1}-\theta\left(H-C_{G 3}\right)-\Delta T_{G 2}-(1-\theta) K_{E 1}-F_{E 1}-C_{G 3}\right]\right. \\
& \left.+C_{G 3}-C_{G 0}-C_{G 1}+\theta\left(H-C_{G 3}\right)+\Delta T_{G 2}+(1-\theta) K_{E 1}\right\} .
\end{aligned}
$$

Therefore, according to the above analysis, the replication dynamic system can be composed of public announcements (4), (8), and (12):

$$
\left\{\begin{array}{l}
\frac{\mathrm{d} x}{\mathrm{~d} t}=F(x)=x\left(U_{x}-\overline{U_{x}}\right)=x(1-x)\left(U_{x}-U_{1-x}\right) \\
=x(1-x)\left\{-y z\left[\theta\left(\alpha K_{Z 1}+K_{Z 2}\right)+(1-\theta) K_{Z 1}\right]-y\left(C_{Z 3}+F_{E 2}\right)+z\left[\theta\left(\alpha K_{Z 1}+K_{Z 2}\right)-\theta K_{Z 1}-K_{Z 2}\right]+K_{Z 1}+K_{Z 2}\right\} \\
\frac{\mathrm{d} y}{\mathrm{~d} t}=F(y)=y\left(U_{y}-\overline{U_{y}}\right)=y(1-y)\left(U_{y}-U_{1-y}\right)=y(1-y)\left(x F_{E 2}+z F_{E 1}+S_{E 1}+S_{E 2}-S_{E 3}+K_{E 2}-C_{E 1}\right), \\
\frac{\mathrm{d} z}{\mathrm{~d} t}=F(z)=z\left(U_{z}-\overline{U_{z}}\right)=z(1-z)\left(U_{z}-U_{1-z}\right) \\
=z(1-z)\left\{x y\left(\theta \alpha K_{Z 1}+C_{G 3}\right)+x\left(C_{G 0}+K_{Z 1}-\theta \alpha K_{Z 1}\right)+y\left[C_{G 1}-\theta\left(H-C_{G 3}\right)-T_{G 1}-(1-\theta) K_{E 1}-F_{E 1}-C_{G 3}\right]\right. \\
\left.\quad+C_{G 3}-C_{G 0}-C_{G 1}+\theta\left(H-C_{G 3}\right)+T_{G 1}+(1-\theta) K_{E 1}\right\} .
\end{array}\right.
$$


At the same time, let the coefficients in formulas (4), (8), and (12) be equal to zero, for example, let the three equations (14), (15), and (16) be equal to zero:

$$
-y z\left[\theta\left(\alpha K_{Z 1}+K_{Z 2}\right)+(1-\theta) K_{Z 1}\right]-y\left(C_{Z 3}+F_{E 2}\right)+z\left[\theta\left(\alpha K_{Z 1}+K_{Z 2}\right)-\theta K_{Z 1}-K_{Z 2}\right]+K_{Z 1}+K_{Z 2}=0
$$

can be obtained separately three equation (17), (18), (19):

$$
\begin{aligned}
& x F_{E 2}+z F_{E 1}+S_{E 1}+S_{E 2}-S_{E 3}+K_{E 2}-C_{E 1}=0 \\
& x y\left(\theta \alpha K_{Z 1}+C_{G 3}\right)+x\left(C_{G 0}+K_{Z 1}-\theta \alpha K_{Z 1}\right)+y\left[C_{G 1}-\theta\left(H-C_{G 3}\right)-T_{G 1}-(1-\theta) K_{E 1}-F_{E 1}-C_{G 3}\right] \\
& \quad+C_{G 3}-C_{G 0}-C_{G 1}+\theta\left(H-C_{G 3}\right)+T_{G 1}+(1-\theta) K_{E 1} \\
& y^{*}=\left(\frac{\left(z\left[\theta\left(\alpha K_{Z 1}+K_{Z 2}\right)-\theta K_{Z 1}-K_{Z 2}\right]+K_{Z 1}+K_{Z 2}\right)}{\left(z\left[\theta\left(\alpha K_{Z 1}+K_{Z 2}\right)+(1-\theta) K_{Z 1}\right]+C_{Z 3}+F_{E 2}\right)}\right) \\
& z^{*}=\left(\frac{\left(-x F_{E 2}-S_{E 1}-S_{E 2}+S_{E 3}-K_{E 2}+C_{E 1}\right)}{F_{E 1}}\right)
\end{aligned}
$$

can get

$$
x^{*}=\left(\frac{-y\left[C_{G 1}-\theta\left(H-C_{G 3}\right)-\Delta T_{G 2}-(1-\theta) K_{E 1}-F_{E 1}-C_{G 3}\right]-C_{G 3}+C_{G 0}+C_{G 1}-\theta\left(H-C_{G 3}\right)-\Delta T_{G 2}-(1-\theta) K_{E 1}}{y\left(\theta \alpha K_{Z 1}+C_{G 3}\right)+\left(C_{G 0}+K_{Z 1}-\theta \alpha K_{Z 1}\right)}\right) .
$$

Based on the replication dynamic system, the Jacobian determinant can be calculated as $J$ [31]:

$$
J=\left[\begin{array}{ccc}
\frac{\partial F(x)}{\partial x} & \frac{\partial F(x)}{\partial y} & \frac{\partial F(x)}{\partial z} \\
\frac{\partial F(y)}{\partial x} & \frac{\partial F(y)}{\partial y} & \frac{\partial F(y)}{\partial z} \\
\frac{\partial F(z)}{\partial x} & \frac{\partial F(z)}{\partial y} & \frac{\partial F(z)}{\partial z}
\end{array}\right],
$$


among them

$$
\left\{\begin{array}{l}
\frac{\partial F(x)}{\partial x}=(1-2 x)\left\{-y z\left[\theta\left(\alpha K_{Z 1}+K_{Z 2}\right)+(1-\theta) K_{Z 1}\right]-y\left(C_{Z 3}+F_{E 2}\right)+Z\left[\theta\left(\alpha K_{Z 1}+K_{Z 2}\right)-\theta K_{Z 1}-K_{Z 2}\right]+K_{Z 1}+K_{Z 2}\right\} \\
\frac{\partial F(x)}{\partial y}=x(1-x)\left\{-z\left[\theta\left(\alpha K_{Z 1}+K_{Z 2}\right)+(1-\theta) K_{Z 1}\right]-\left(C_{Z 3}+F_{E 2}\right)\right\} \\
\frac{\partial F(x)}{\partial z}=x(1-x)\left\{-y\left[\theta\left(\alpha K_{Z 1}+K_{Z 2}\right)+(1-\theta) K_{Z 1}\right]+\left[\theta\left(\alpha K_{Z 1}+K_{Z 2}\right)-\theta K_{Z 1}-K_{Z 2}\right]\right\} \\
\frac{\partial F(y)}{\partial x}=y(1-y) F_{E 2} \\
\frac{\partial F(y)}{\partial y}=(1-2 y)\left(x F_{E 2}+z F_{E 1}+S_{E 1}+S_{E 2}-S_{E 3}+K_{E 2}-C_{E 1}\right) \\
\frac{\partial F(y)}{\partial z}=y(1-y) F_{E 1}, \\
\frac{\partial F(z)}{\partial x}=z(1-z)\left[y\left(\theta \alpha K_{Z 1}+C_{G 3}\right)+C_{G 0}+K_{Z 1}-\theta \alpha K_{Z 1}\right] \\
\frac{\partial F(z)}{\partial y}=z(1-z)\left[y\left(\theta \alpha K_{Z 1}+C_{G 3}\right)+C_{G 1}-\theta\left(H-C_{G 3}\right)-T_{G 1}-(1-\theta) K_{E 1}-F_{E 1}-C_{G 3}\right] \\
\frac{\partial F(z)}{\partial z}=(1-2 z)\left\{x y\left(\theta \alpha K_{Z 1}+C_{G 3}\right)+y\left[C_{G 1}-\theta\left(H-C_{G 3}\right)-T_{G 1}-(1-\theta) K_{E 1}-F_{E 1}-C_{G 3}\right]\right. \\
\left.+x\left(C_{G 0}+K_{Z 1}-\theta \alpha K_{Z 1}\right)+C_{G 3}-C_{G 0}-C_{G 1}+\theta\left(H-C_{G 3}\right)+T_{G 1}+(1-\theta) K_{E 1}\right\} .
\end{array}\right.
$$

The determinant of the Jacobian matrix $\operatorname{det} J$ and the trace of the matrix $\operatorname{tr} J$ can be obtained by calculation (Table 3).

Based on the relevant data, this paper substitutes formulas (4), (8), and (12) into the regulatory change rate, repair rate of change, and execution rate (Figure 1), and at the same time, the basic data are substituted into dozens of external variables (Table 4).

\section{Simulation Analysis Assignment}

Based on the system dynamics simulation model, according to the assigned data, we can get Figure 2-Figure 17. The economic activities of rare-earth mining companies are limited, and they are more concerned about whether repairing the environment can bring higher economic benefits to the company. When the company does not carry out ecological restoration, it can obtain higher economic returns than when it chooses not to repair it, and after paying the central and local government's fines, the company still has a profit. Then, mining companies will take the risk and choose not to repair the strategy and abandon the repair work of rare-earth mines. The central government and local governments will punish the offending companies when they choose not to repair the strategy. However, the central government and local governments have not imposed severe penalties. The payment of fines by rare-earth mining companies will not affect their business activities, so the rare-earth companies will continue to mine rare-earth and refuse to repair the ecological environment (Figure 2). This situation shows that the central and local governments have certain shortcomings in the ecological environment reward and punishment mechanism, and lowintensity economic punishment measures are difficult to change the current situation of difficult ecological environment restoration. This section will perform a numerical analysis of various influencing factors, find out the key factors that affect the choice of the three-party game strategy, and provide theoretical support for the government to formulate a scientific and reasonable rare-earth environmental governance policy. 


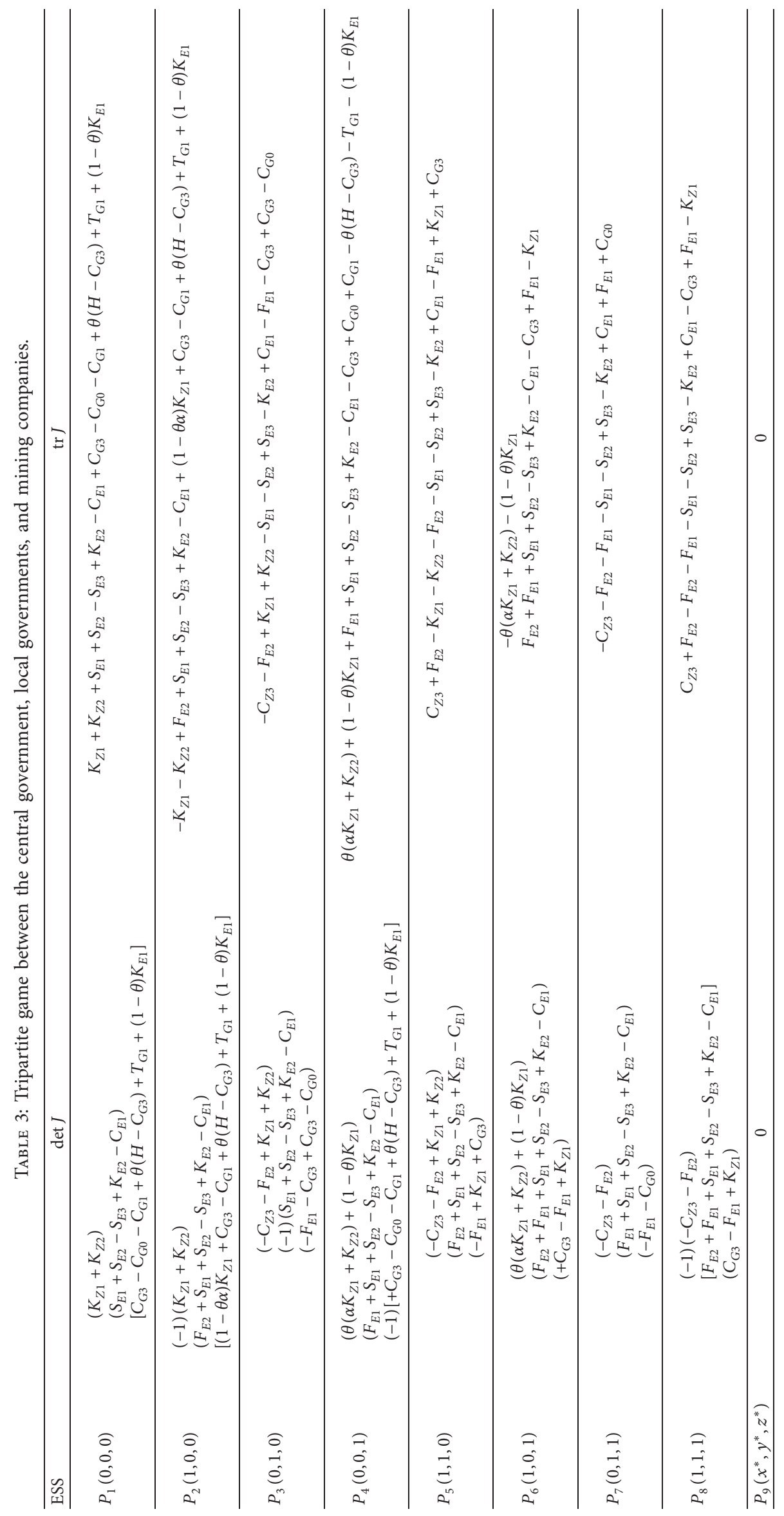




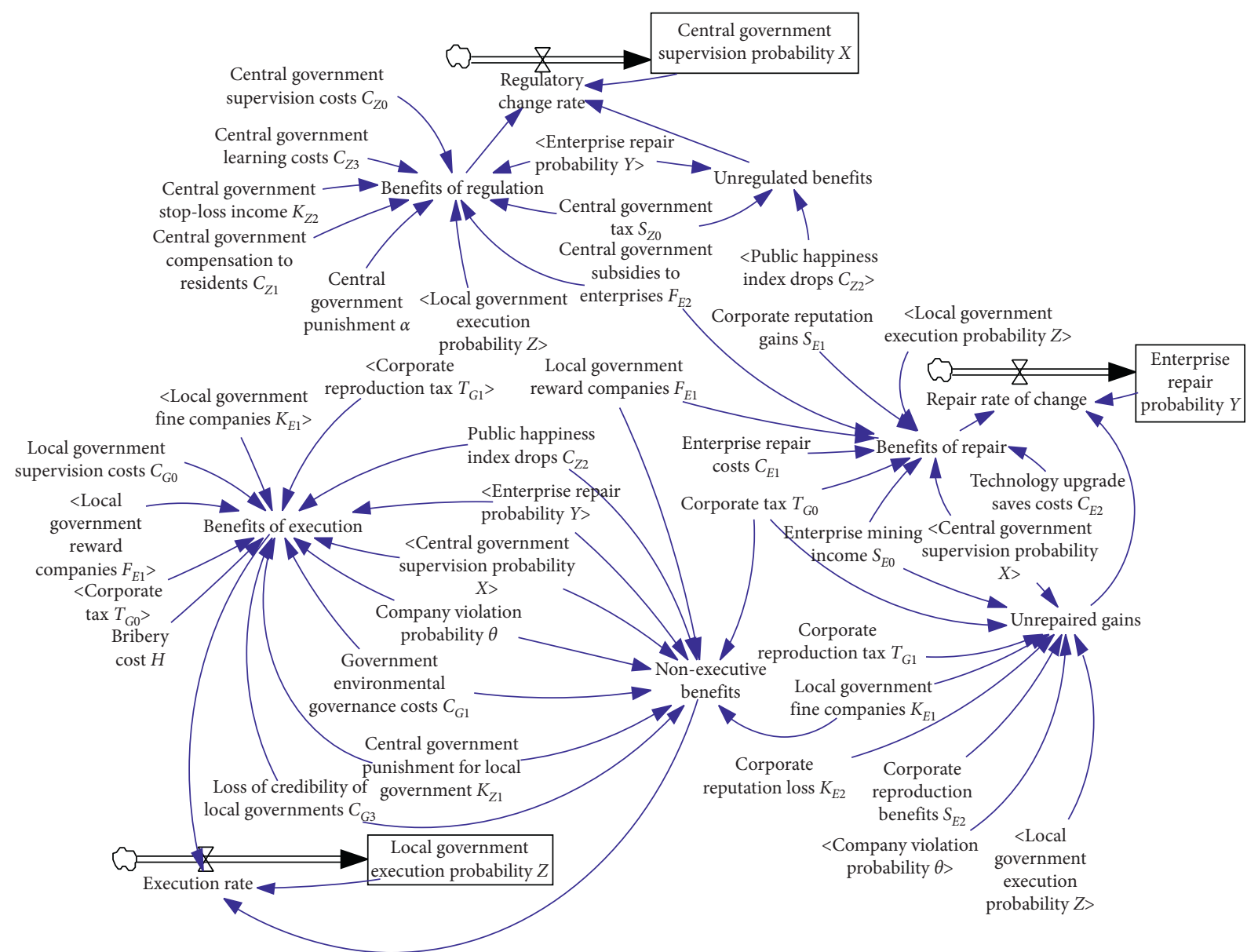

FIGURE 1: Tripartite evolution of system dynamics.

TABle 4: Assignment table.

\begin{tabular}{lcc}
\hline Parameter & Assignment & Meaning \\
\hline$S_{E 0}$ & 2.4 & Enterprise mining income \\
$C_{E 1}$ & 1.4 & Enterprise repair costs \\
$S_{E 1}$ & 0.6 & Corporate reputation gains \\
$S_{E 2}$ & 0.55 & Corporate reproduction benefits \\
$F_{E 1}$ & 0.5 & Local government reward companies \\
$K_{E 1}$ & 1.8 & Local government fine companies \\
$K_{E 2}$ & 0.4 & Corporate reputation loss \\
$K_{Z 2}$ & 0.4 & Central government stop-loss income \\
$C_{Z 1}$ & 0.9 & Central government compensation to residents \\
$C_{Z 2}$ & 0.2 & Public happiness index drops \\
$C_{Z 3}$ & 1.3 & Central government learning costs \\
$F_{E 2}$ & 0.65 & Central government subsidies to enterprises \\
$T_{G 0}$ & 0.43 & Corporate tax \\
$C_{G 1}$ & 1 & Government environmental governance costs \\
$C_{E 2}$ & 0.7 & Technology upgrade saves costs \\
$C_{G 0}$ & 0.62 & Local government supervision costs \\
$T_{G 1}$ & 0.2 & Corporate reproduction tax \\
$C_{G 3}$ & 0.8 & Loss of credibility of local governments \\
$S_{Z 0}$ & 1.5 & Central government tax \\
$K_{Z 1}$ & 1.2 & Central government punishment for the local government \\
$C_{Z 0}$ & 0.52 & Central government supervision costs \\
$\theta$ & 0.35 & Company violation probability \\
$H$ & 0.9 & Bribery cost \\
$\alpha$ & 0.75 & Central government punishment
\end{tabular}




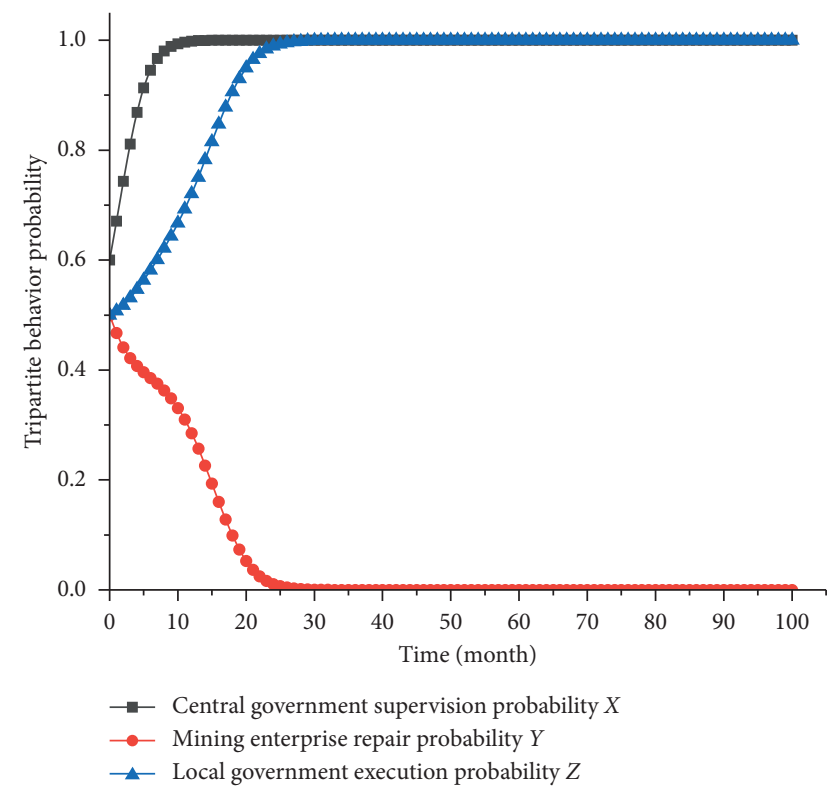

FIGURE 2: Initial state probability curve of the tripartite game between governments at all levels and mining enterprises.

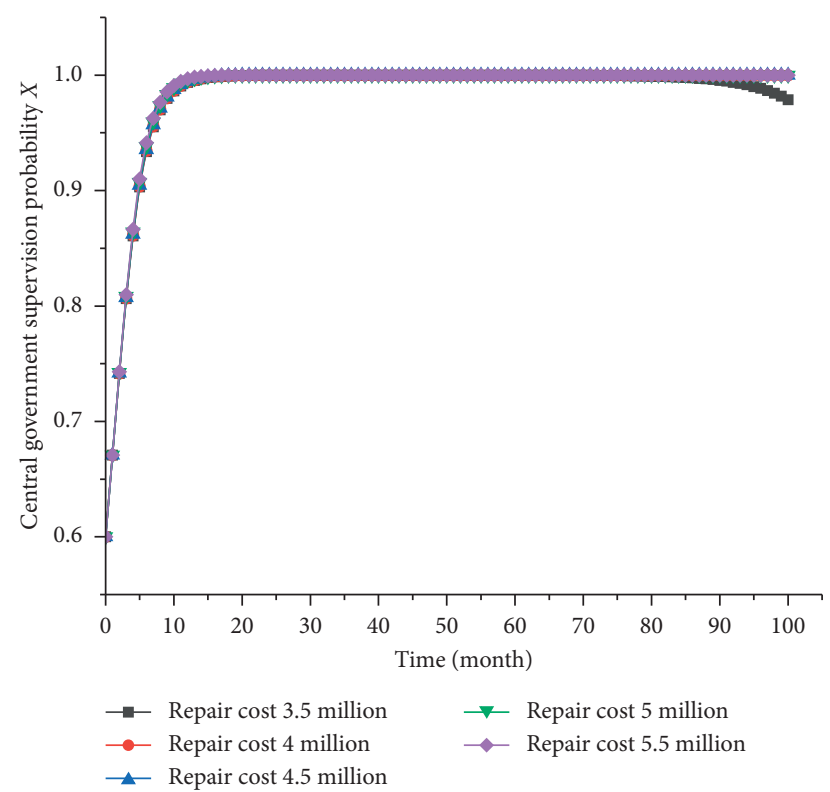

Figure 3: The impact of repair costs on central government strategy choices.

Figures 3-5 can be obtained by changing the repair cost quota of rare-earth mining enterprises. These three maps, respectively, represent the central government, mining enterprises, and local governments affected by the repair cost quota. As can be seen from Figure 3, the central government's sensitivity to the cost of repair is extremely low, and the central government's strategy has only slightly changed in five cases. However, it can be seen from the change trends of the curves in Figures 4 and 5 that the changes in the repair cost of the enterprise have the same change trend for the mining enterprises and local governments, but the change

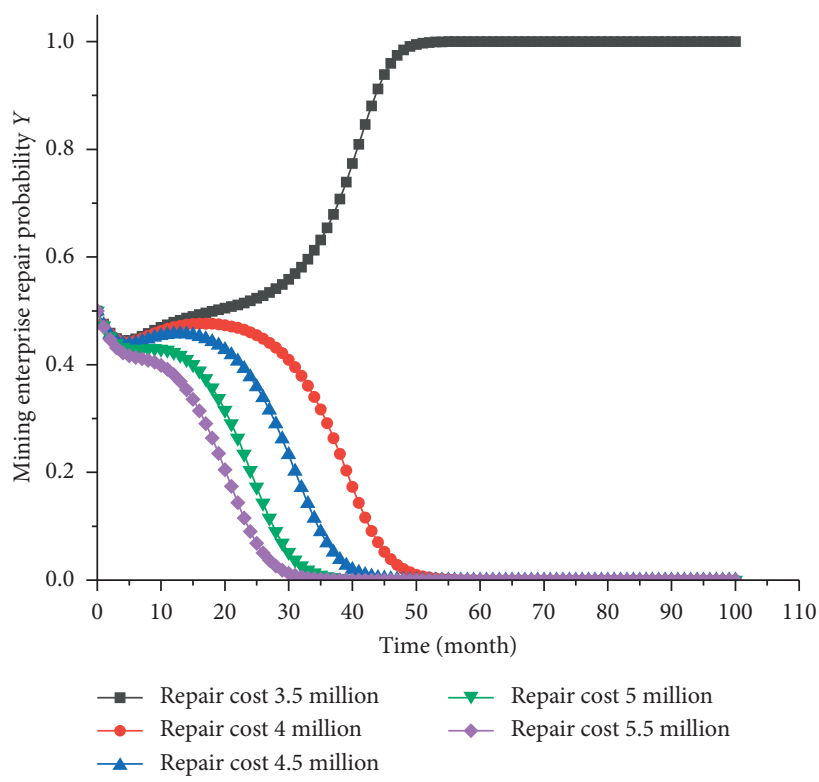

FIgURE 4: Impact of remediation costs on strategic choices of mining enterprises.

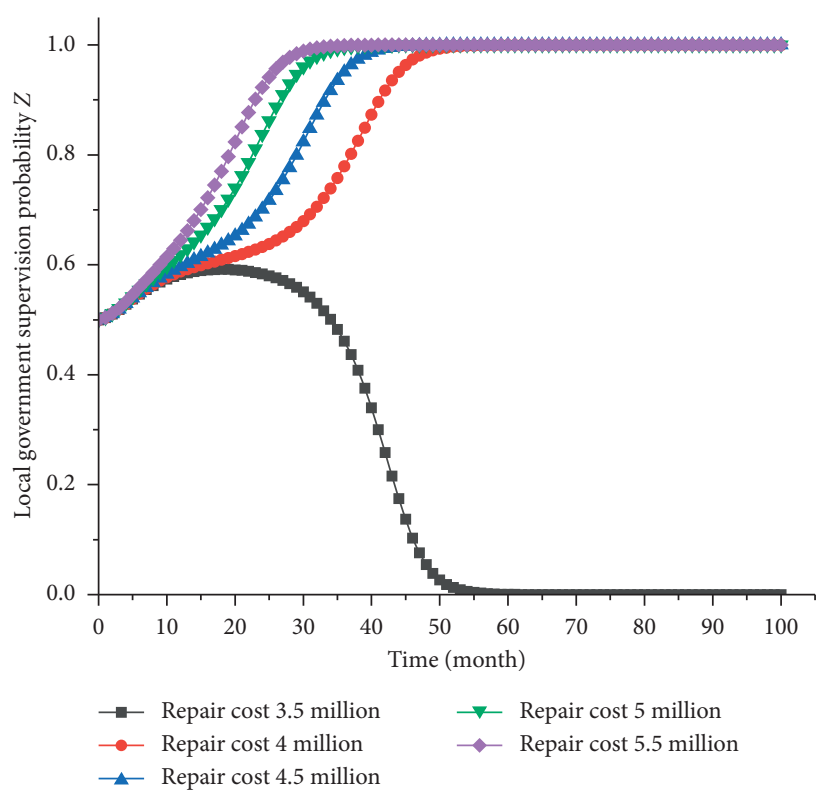

FIGURE 5: Impact of repair costs on local government strategy choices.

direction is the opposite. When a rare-earth mining company chooses not to repair the ecological environment strategy, the local government will take measures to supervise the rare-earth mining company, but when the mining company chooses to repair the ecological environment strategy, the local government will gradually choose a nonsupervision strategy to reduce financial pressure. When the repair cost of a rare-earth mining company is 4 million or more, the rare-earth mining company will choose not to repair the strategy, and the local government will choose a regulatory strategy. The repair cost of rare-earth mining 


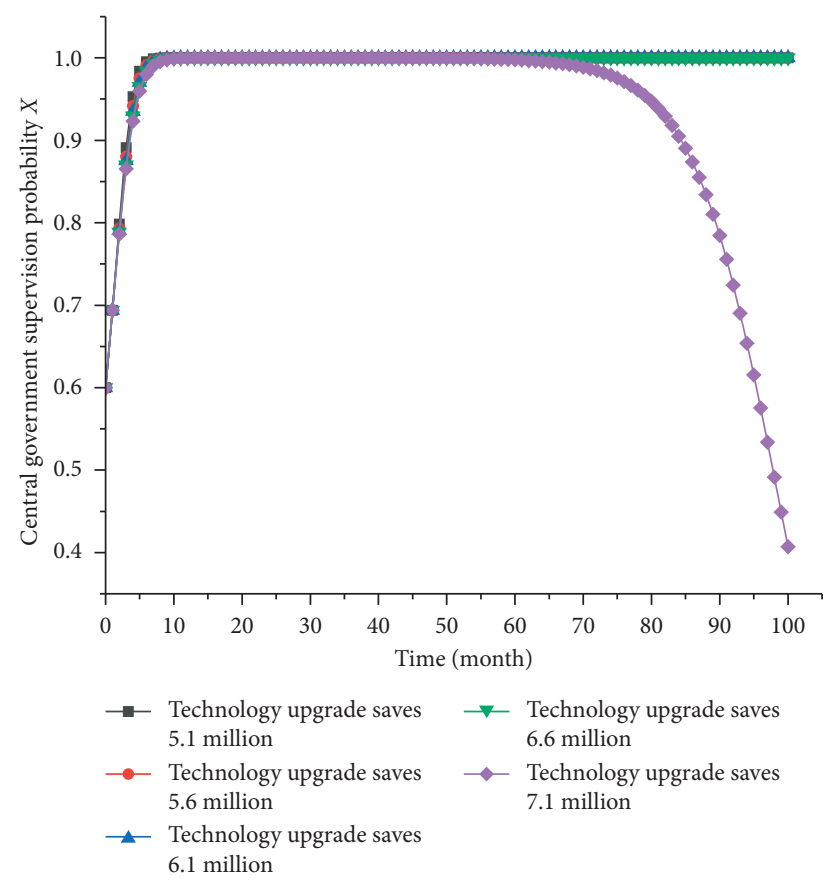

FIGURE 6: Impact of technology upgrade cost savings on central government strategy choices.

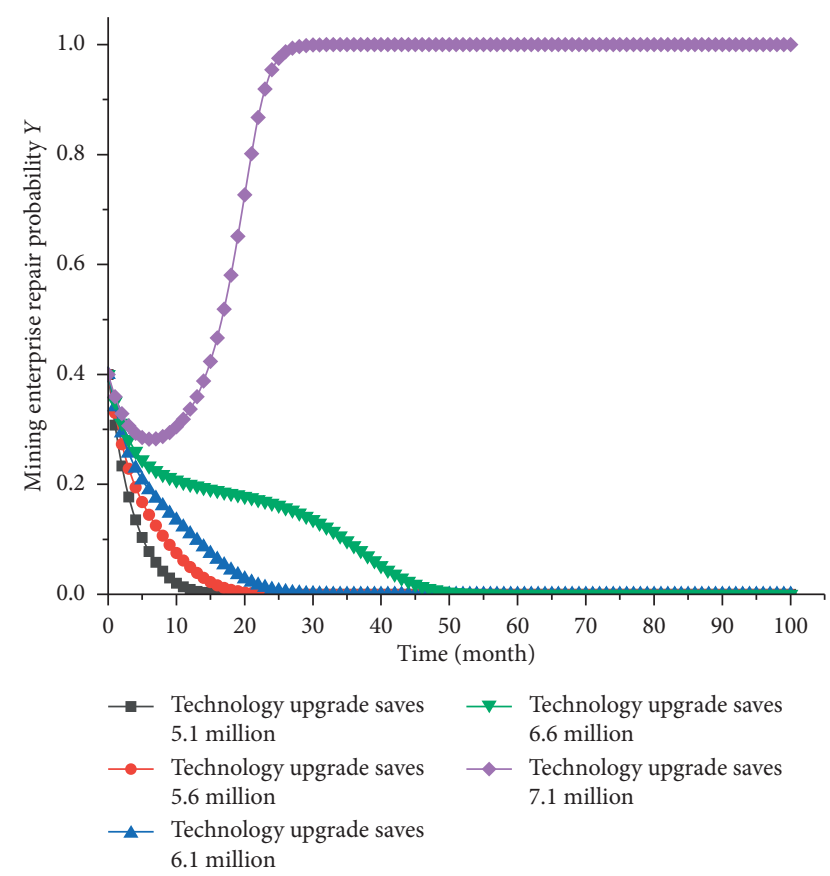

FIGURE 7: Impact of technology upgrade cost savings on mining companies' strategic choices.

enterprises can change the strategic choices of local governments and mining enterprises, but it has little effect on the central government, which indicates that the independent behavior of the enterprises has a smaller scope of influence, and local governments and rare-earth mining enterprises pay more attention to their own interests. The central government is more concerned about the state of

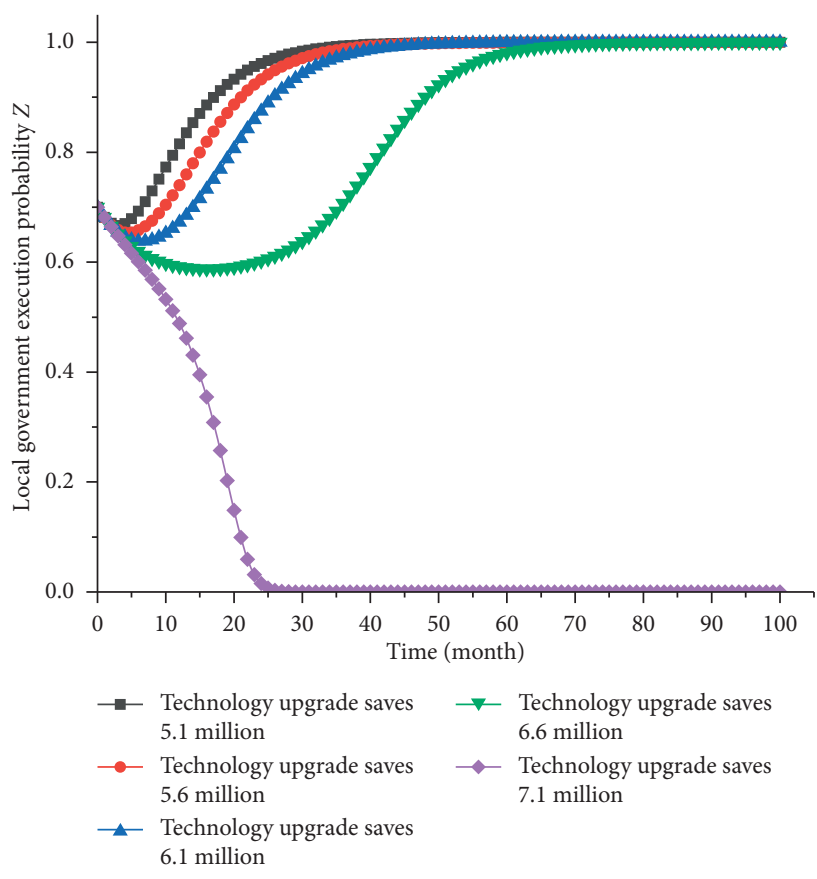

Figure 8: Impact of technology upgrade cost savings on local government strategy choices.

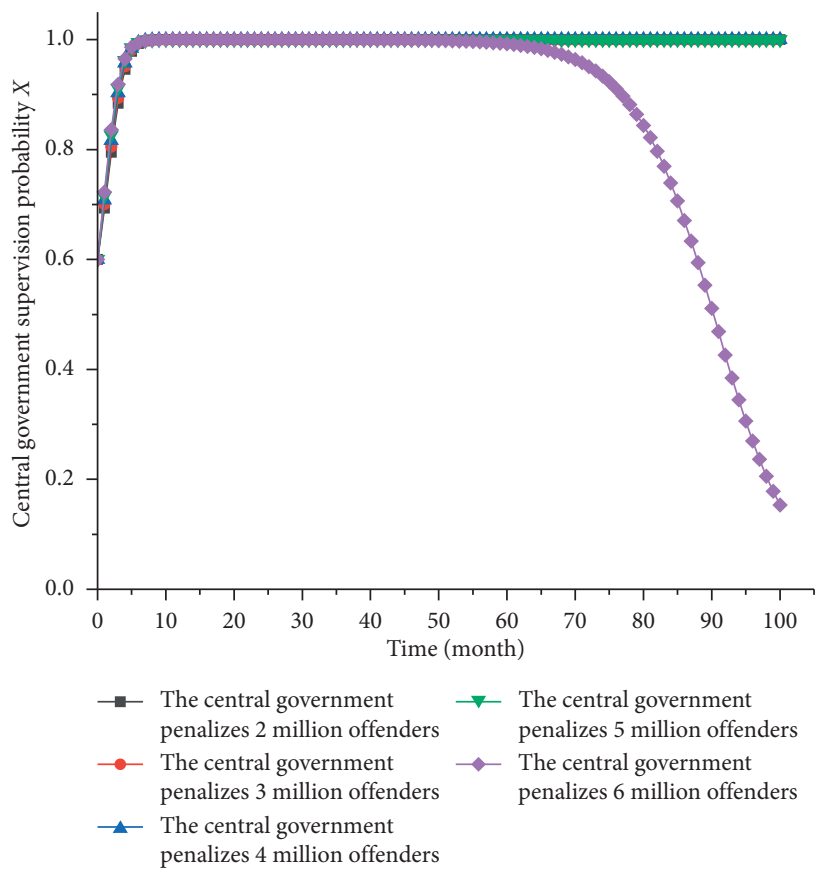

FIGURE 9: Impact of central fines on central government strategy choices.

development of the whole society. How to deal with local ecological environment governance through restoration costs will become an important factor in dealing with the game between local governments and mining enterprises.

By changing the technology upgrade of the rare-earth mining enterprises to save costs, Figures 6-8 can be obtained. These three maps represent the central government, 


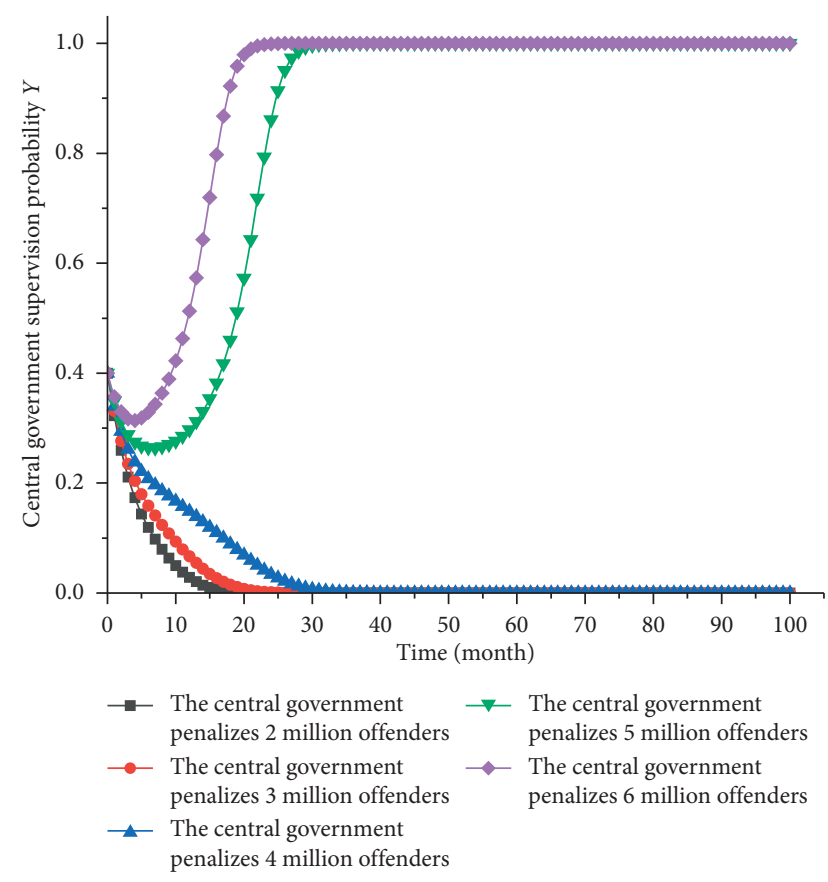

FIGURE 10: Impact of central fines on mining companies' strategic choices.

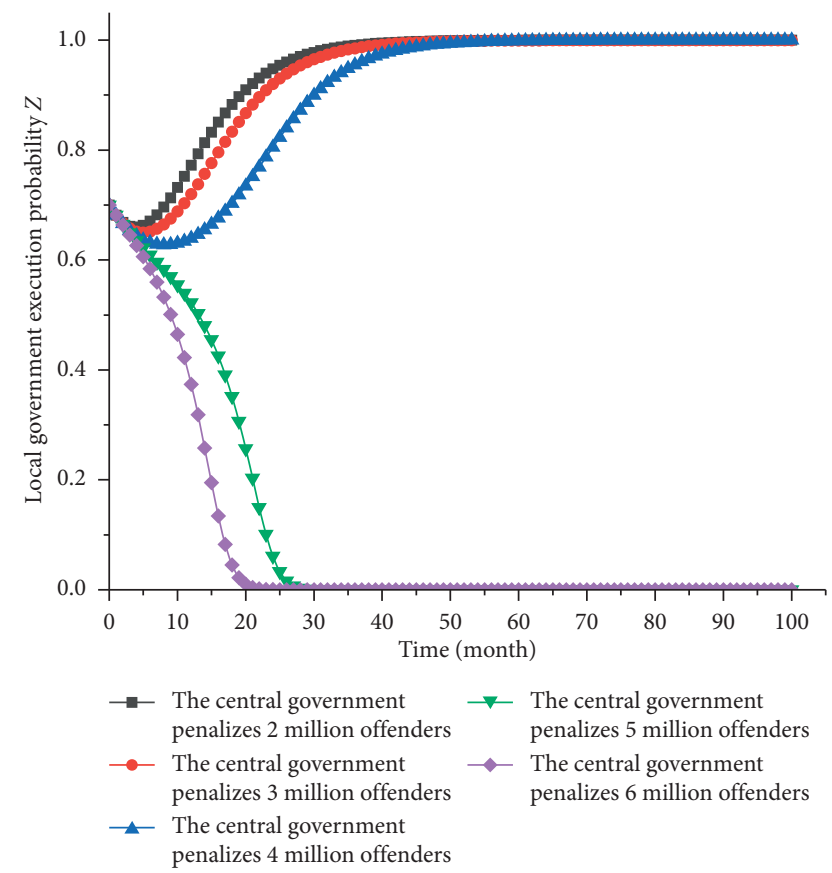

FIGURE 11: Impact of central fines on strategic choices of local governments.

mining enterprises, and local governments, which are affected by the technology upgrade and cost savings. It can be seen from Figure 6 that, in the initial stage of the project, the cost savings of technology did not have a strong impact on the central government's strategy. At 70 months, the high cost of technological savings caused the central government's strategy to begin to evolve towards the direction of

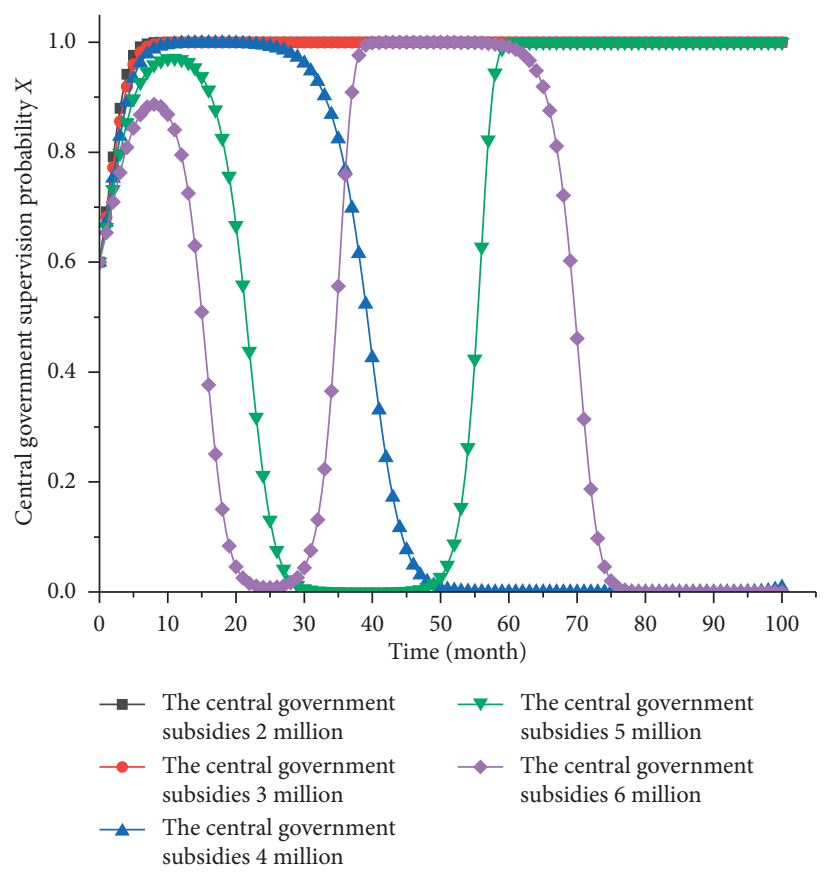

FIGURE 12: The impact of central subsidies on central government strategy choices.

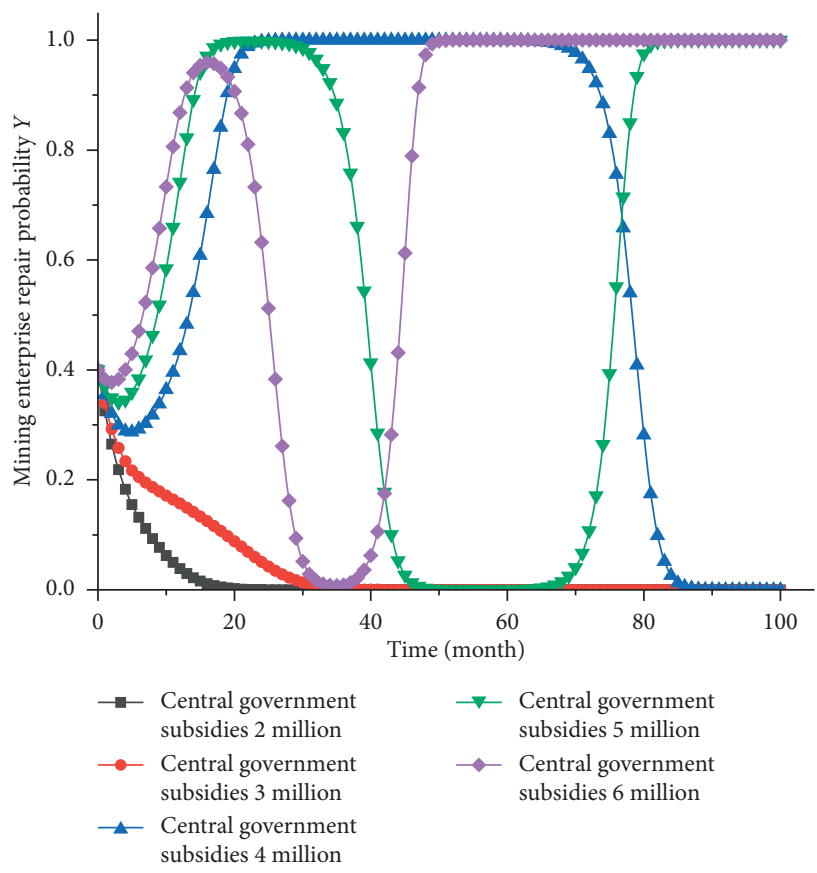

FIgURE 13: The impact of central subsidies on mining companies' strategic choices.

nonregulation. As can be seen from Figures 7 and 8, the cost savings of different technology upgrades in the early stages of the project made a difference in the strategic choices of mining companies and local governments. With the development of the project, for the mining companies, the technological cost saving increasing means increasing the probability of mining companies choosing repair strategies 


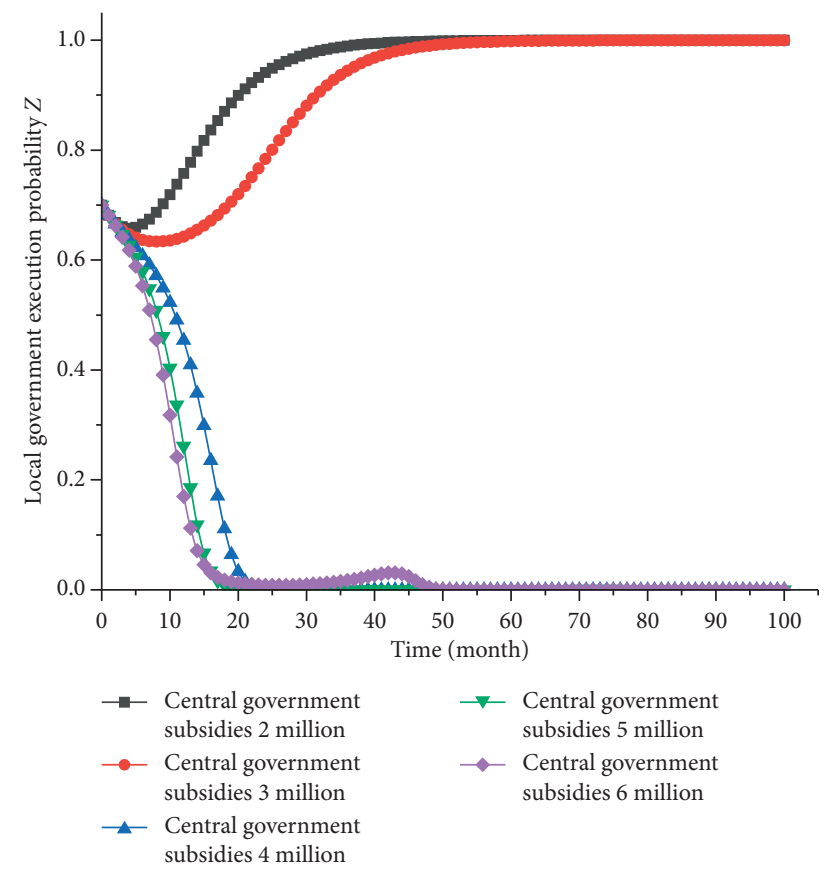

Figure 14: The effect of central subsidies on the selection of local government strategies.

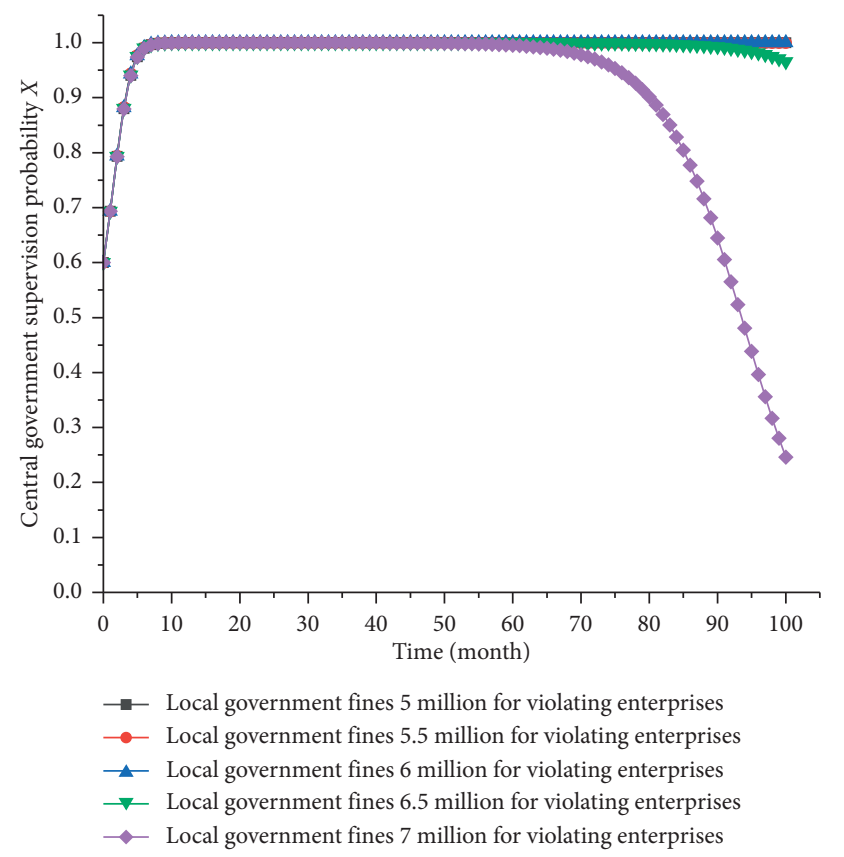

Figure 15: The impact of local fines on central government strategy choices.

and speeding up to equilibrium. When the strategic choice of rare-earth mining enterprises changes, local governments are under financial pressure and environmental governance considerations, which will gradually reduce the intensity of supervision of enterprises, and over time, local governments gradually prefer nonregulated strategic choices. It can be seen from the comparison of the three pictures that the cost savings of technological upgrades will have a certain degree

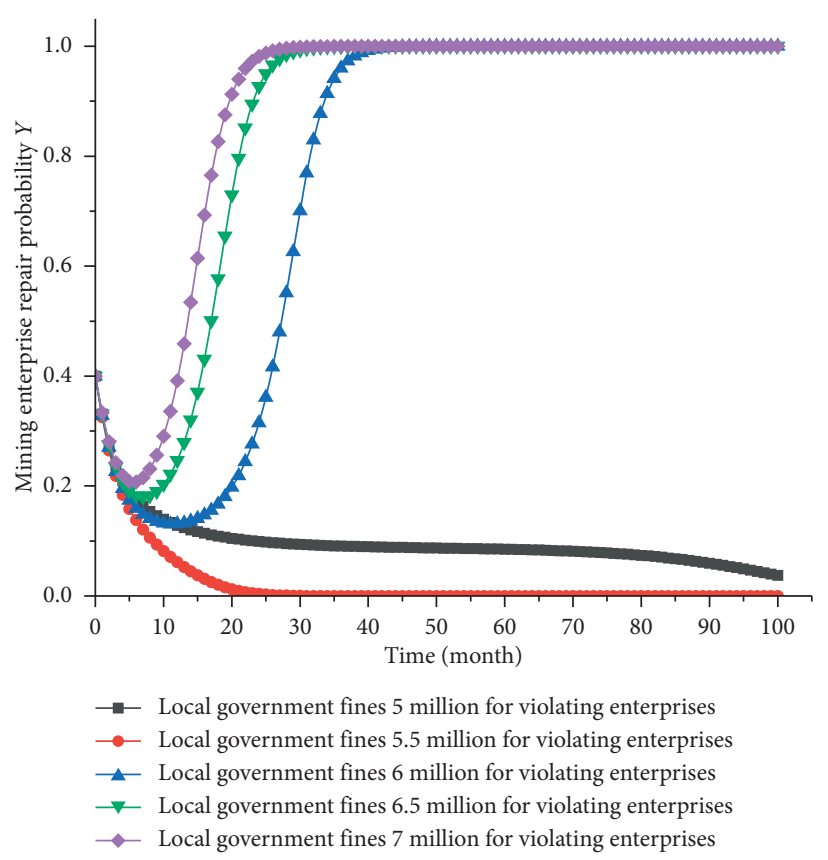

Figure 16: The impact of local fines on the strategic choice of mining companies.

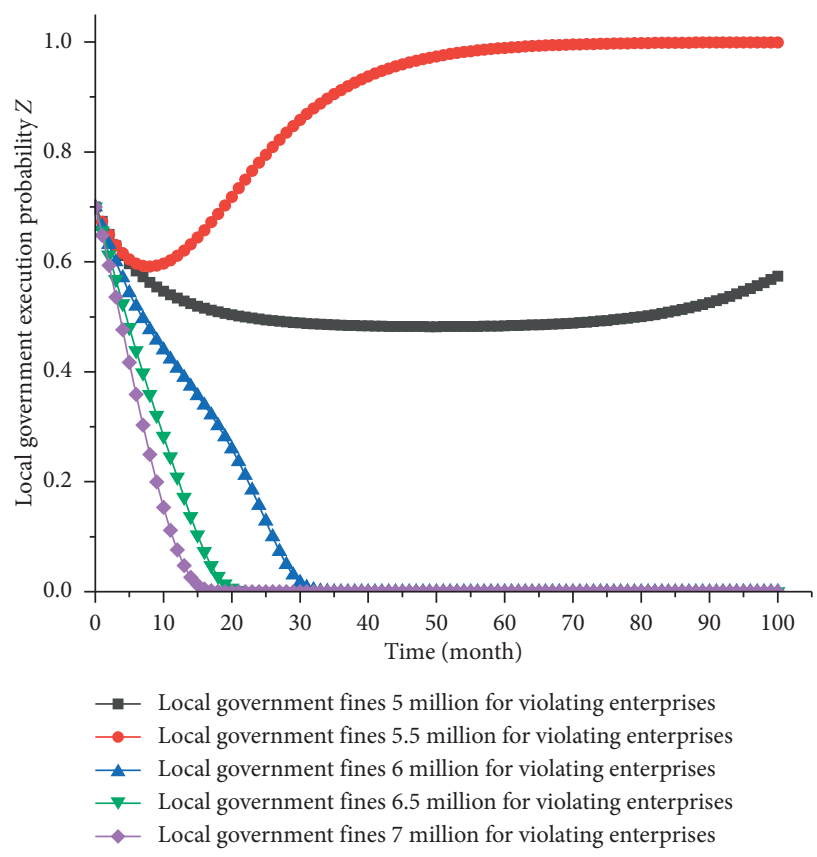

FIgURE 17: The impact of local fines on local government strategy choices.

of influence on the strategic choices of the three parties. Technology upgrades have lower cost savings, but the main reason that can affect the choice of the corporate strategy is that the cost can affect the future financial situation of the enterprise in the form of depreciation in the financial statements of the enterprise and then affect the strategic choice of the enterprise. When the amount of technology cost savings rises to a certain level, it will have a strong 
impact on the strategic choices of the central government, mining enterprises, and local governments. It can be seen that mining enterprises should improve the conversion and application of science and technology in the mining, smelting, and separation of rare-earths, reduce the cost of expenditures, and reduce the loss of the ecological environment by the rare-earth industry. Local and central governments should also introduce relevant incentive policies to encourage rare-earth mining companies to invest in technology upgrades.

Figures 9-11 can be obtained by changing the fines imposed by the central government on mining enterprises. These three maps represent the trends of the central government, mining enterprises, and local governments affected by the fines imposed by the central government on local governments. It can be seen from Figure 9 that, in the early stage of the project, the fines of the central government did not have a strong impact on the choice of the central government's strategy. At 60 months, the high central fines prompted the central government's strategy to start to evolve towards nonregulation. From Figures 10 and 11, it can be seen that local governments and mining companies are more sensitive to central fines. With the change in the central fines, when the central fines are 4 million, mining enterprises are more inclined to choose environmental remediationstrategies. During the same period, the central government maintained a regulatory posture, which eventually prompted mining companies to choose a strategy to repair the environment steadily. When mining companies choose not to repair, local governments will choose surveillance strategies. On the one hand, they are worried about the inspection and punishment of the central government, and on the other hand, they are for the local ecological environment. When mining companies begin to choose environmental remediation strategies, local governments will reduce the intensity of surveillance and eventually choose strategies that do not. At the same time, it can also be seen from the change in the value of the central fines that the greater the central government's punishment for speculation by local governments, the faster the mining companies can reach a stable state of restoring environmental strategies. This shows that even under the supervision of the central government, as long as mining companies are willing to repair the environment, local governments may have speculation. The main reason is that the rationality of local government managers is limited, and local government officials will not only worry about their units' financial pressure, but also want to save money and effort in a way to get better results in higher-level assessments.

Figures 12-14 can be obtained by changing the subsidy of the central government to mining enterprises. These three maps represent the trend of the central government, mining enterprises, and local governments affected by the central government's subsidies to mining enterprises. It can be seen from Figures 12-14 that the change in the subsidy quota of the central government has a strong impact on the strategic choices of the three parties: the central government, mining enterprises, and local governments. As can be seen from Figure 12, lower central subsidy quotas cannot wholly change the central government's strategic choices, but with the increase of central subsidy quotas, the situation of each subsidy quota will slow down the central government's speed of achieving regulatory stability. However, the high amount of central subsidies has made the central government's strategy unstable, and with the increase in the number of seed subsidies, the instability of the central government's strategic choices has gradually increased. Similarly, comparing the strategic choices of mining enterprises with those of the central government, we can see that the fluctuation of the central government's strategic decisions is caused by the transformation of the mining enterprises' strategic choices. The low amount of central subsidies is not enough to change the mining company's strategic selection. Although a small number of mining companies choose to repair the strategy, once the central subsidy ceases to be issued, the mining company will gradually decide not to repair the procedure. The high subsidies allow mining companies to obtain sufficient economic benefits, so when the central subsidy is no longer issued, mining companies will still choose a repair strategy. However, this strategy will increase the financial pressure of the central government, which is not conducive to the sustainable development of the mining industry's ecological industry. When the mining company's strategic choices begin to move closer to the restoration strategy, local governments will gradually reduce the intensity of supervision and eventually choose a nonsupervision policy.

By changing the subsidies of local governments to mining enterprises, Figures 15-17 can be obtained. These three maps represent the central government, mining enterprises, and local governments, respectively, and are affected by local government penalties for mining enterprises. It can be seen from Figure 15 that, in the early stage of the project, local government fines did not have a substantial impact on the central government's strategic choices. At 65 months, the high local fines prompted the central government's strategy to start to evolve towards nonregulation. This shows that local fines have a lower impact on the central government's strategic choices. From the comparison between Figures 16 and 17, it can be seen that local governments and mining companies are more sensitive to the factors of local fines. With the increase of local fines, mining companies will gradually choose repair strategies in order to reduce economic losses. Similarly, the higher the local fine, the faster the mining company can reach a steady state of the repair strategy. It can be seen that local governments must strengthen their behavioral control over mining enterprises in order to improve the local ecological environment and promote the green transformation of enterprises.

\section{Conclusion}

This article constructs a three-party evolutionary game model for the central government, local government, and local enterprises. Through progressive stability analysis and system dynamics simulation models, it explores the evolution process of the three-party primary body strategy selection and finds out the key factors that affect the environmental management of rare-earths. The simulation results show that the central 
government's punishment to local governments, the central government's subsidies to mining enterprises, and the local government's punishment to local enterprises are the key factors affecting the environmental management of rareearths. By adjusting the reward and punishment measures, the model finds that it can effectively change the state of the strategy and promote the ecological restoration of mining. At the same time, this study brings the following enlightenment to management: (i) the central government should establish and improve the central government's supervision and management mechanism for local governments and mining enterprises as soon as possible. At the same time, the central government should also strengthen the reward mechanism and punishment mechanism to improve the economic and social benefits of rare-earth mining enterprises and local governments in restoring the ecological environment. (ii) Mining enterprises should have the courage to take responsibility for ecological environment management. Government departments wanting rare-earth mining companies to participate in the restoration of the ecological environment truly, they must implement a double reward-punishment measure, which not only pressures the rare-earth mining companies but also can alleviate the pressure on the company's ecological restoration to a certain extent and promote enterprises to voluntarily and autonomously geo-ecological restoration road. Local governments should implement the decisions of the central government, increase their supervision over rare-earth mining enterprises, and raise their own level of supervision. Local governments must severely punish mining companies that have violated regulations, and at the same time, they must commend ecologically repaired rareearth mining companies and promote related enterprises to trigger a chain reaction. The article analyzes the game based on the tripartite subjects of the central government, mining enterprises, and local governments. However, in the actual operation process, the reality is often more complicated, and it is necessary to consider the relationship between neighboring enterprises and the work and the interaction between neighboring regions in many aspects. This point is also the future direction of this research.

\section{Conflicts of Interest}

The authors declare no conflicts of interest.

\section{Acknowledgments}

First of all, the authors are very grateful for the support of Vensim software and Origin software for this research. Secondly, this work was supported by Science and Technology Project of Jiangxi Provincial Department of Education (GJJ190455).

\section{References}

[1] J. Fan, D. Jiang, W. Liu, F. Wu, J. Chen, and J. Daemen, "Discontinuous fatigue of salt rock with low-stress intervals," International Journal of Rock Mechanics and Mining Sciences, vol. 115, pp. 77-86, 2019.
[2] F. Pan, B. Xi, and L. Wang, "Game analysis of the evolution of local government and central government in environmental regulation," Operations Research and Management, vol. 24, no. 3, pp. 88-93, 2015.

[3] L. Niu, F. Wang, C. Zang, W. Shang, and S. Zhang, "Hybrid model based on wavelet transform and ARIMA for short-term electricity price forecasting," Application Research of Computers, vol. 31, no. 3, pp. 688-691W, 2014.

[4] W. Qiao, K. Huang, M. Azimi, and S. Han, "A novel hybrid prediction model for hourly gas consumption in supply side based on improved whale optimization algorithm and relevance vector machine," IEEE Access, vol. 7, pp. 88218-88230, 2019.

[5] J. Chen, D. Lu, W. Liu et al., "Stability study and optimization design of small-spacing two-well (SSTW) salt caverns for natural gas storages," Journal of Energy Storage, vol. 27, Article ID 101131, 2020.

[6] W. Qiao, W. Tian, Y. Tian, Q. Yang, Y. Wang, and J. Zhang, "The forecasting of PM2.5 using a hybrid model based on wavelet transform and an improved deep learning algorithm," IEEE Access, vol. 7, pp. 142814-142825, 2019.

[7] W. Qiao and Z. Yang, "Solving large-scale function optimization problem by using a new metaheuristic algorithm based on quantum dolphin swarm algorithm," IEEE Access, vol. 7, pp. 138972-138989, 2019.

[8] W. Qiao and Z. Yang, "Modified dolphin swarm algorithm based on chaotic maps for solving high-dimensional function optimization problems," IEEE Access, vol. 7, pp. 110472110486, 2019.

[9] W. Qiao and Z. Yang, "An improved dolphin swarm algorithm based on kernel fuzzy C-means in the application of solving the optimal problems of large-scale function," IEEE Access, vol. 8, pp. 2073-2089, 2020.

[10] W. Qiao, H. Lu, G. Zhou, M. Azimi, Q. Yang, and W. Tian, “A hybrid algorithm for carbon dioxide emissions forecasting based on improved lion swarm optimizer," Journal of Cleaner Production, vol. 244, Article ID 118612, 2020.

[11] Z. Zhang, D. Jiang, W. Liu et al., "Study on the mechanism of roof collapse and leakage of horizontal cavern in thinly bedded salt rocks," Environmental Earth Sciences, vol. 78, p. 292, 2019.

[12] G. Zhou, H. Moayedi, M. Bahiraei, and Z. Lyu, "Employing artificial bee colony and particle swarm techniques for optimizing a neural network in prediction of heating and cooling loads of residential buildings," Journal of Cleaner Production, vol. 254, Article ID 120082, 2020.

[13] C. Zhong, N. Hu, S. Duan, N. Zhang, G. Xiu, and G. Li, "Research on evaluation system of nonferrous metal green mine," Mining Research and Development, vol. 39, no. 7, pp. 146-151, 2019.

[14] M. Zheng and T. Luo, "Quantitative research on water environment cost of ionic rare-earth mines in south Jiangxi," Rare Earths, vol. 40, no. 5, pp. 147-158, 2019.

[15] L. Su and A. Cheng, "Environmental performance evaluation index system and model construction of rare-earth enterprises," Friends of Accounting, no. 24, pp. 84-88, 2016.

[16] S. Xu, H. Zhang, C. Xu, and L. Xu, "Research on ecological safety evaluation of ionic rare-earth mining areas based on PSR model," Science and Technology Management Research, vol. 38, no. 15, pp. 263-267, 2018.

[17] Y. Yu, D. Wang, J. Gao, L. Liu, W. Wang, and S. Zhang, “A review of ore prospecting techniques and applications in China's three rare earths," Acta Geologica Sinica, vol. 93, no. 6, pp. 1533-1542, 2019. 
[18] J. Wang and Y. Zhang, "Environmental regulation, green technology innovation willingness and green technology innovation behavior," Scientific Research, vol. 36, no. 2, pp. 352-360, 2018.

[19] F. Pan, B. Xi, and L. Wang, "Evolutionary game analysis of environmental regulation strategies among local governments," China Population-Resources and Environment, vol. 24, no. 6, pp. 97-102, 2014.

[20] Z. Chen and W. Wang, "Game analysis of the evolution of government and polluting enterprises under the environmental tax system," Management Review, vol. 29, no. 5, pp. 226-236, 2017.

[21] F. Pan, B. Xi, and L. Wang, "Analysis of local government environmental regulation strategy based on evolutionary game," Systems Engineering Theory \& Practice, vol. 35, no. 6, pp. 1393-1404, 2015.

[22] Z. Guo, K. Zhao, J. Jin, G. Wang, and Y. Zhu, "Research progress on environmental risk assessment and pollution control of ionic rare earth ore," Rare Earths, vol. 40, no. 3, pp. 115-126, 2019.

[23] A. Mohammadi, H. Lashini, M. Habibi, and H. Safarpour, "Influence of viscoelastic foundation on dynamic behaviour of the double walled cylindrical inhomogeneous micro shell using MCST and with the aid of GDQM," Journal of Solid Mechanics, vol. 11, pp. 440-453, 2019.

[24] H. Safarpour, S. A. Ghanizadeh, and M. Habibi, "Wave propagation characteristics of a cylindrical laminated composite nanoshell in thermal environment based on the nonlocal strain gradient theory," The European Physical Journal Plus, vol. 133, no. 12, p. 532, 2018.

[25] W. Gao, W. Wang, D. Dimitrov, and Y. Wang, "Nano properties analysis via fourth multiplicative abc indicator calculating," Arabian Journal of Chemistry, vol. 11, no. 6, pp. 793-801, 2016.

[26] G. Zhou, H. Moayedi, and L. K. Foong, "Teaching-Learningbased metaheuristic scheme for modifying neural computing in appraising energy performance of building," Engineering with Computers, vol. 36, 2020.

[27] Y. Cao, Z. Yu, and G. Wan, "Research on the evolutionary game between government and enterprise in food adulteration under the new media environment," China Management Science, vol. 25, no. 6, pp. 179-187, 2017.

[28] T. Yu and C. Liu, "Evolutionary game analysis and simulation research on government and third party in product quality supervision," China Management Science, vol. 6, pp. 90-96, 2016.

[29] Y. Zhao, B. Guo, and S. Liu, "A multiparty game model for product quality supervision under incomplete information," China Management Science, vol. 25, no. 2, pp. 111-120, 2017.

[30] G. Li, "Research on the influence of government regulation on enterprise dispatching behavior based on evolutionary game analysis," Management Review, vol. 31, no. 10, pp. 191-199, 2019.

[31] Q. Kong, Q. Zhang, X. Yang, and J. Shi, "Research on the evolution and simulation of product cluster product quality supervision," China Management Science, pp. 1-16, 2020. 